\title{
Trabajos prácticos: una reflexión acerca de mi quehacer como Profesora de Biología
}

Por: Ruiz Vargas Dolly Margaret ${ }^{1}$

Recibido: 19-12-2008

Aceptado: 27-05-2009

Visitar una granja, recorrer un humedal, colectar insectos, observar el crecimiento de una planta en un vivero, diseccionar un corazón, hacer un herbario, observar células al microscopio, explorar el patio de la escuela en compañía de una lupa, hacer ilustraciones de todo ello, registrar datos, graficar y analizar a la luz de las teorías los resultados, son trabajos prácticos propios de mi experiencia docente.

Semana tras semana, mes tras mes y año tras año durante la última década he procurado plantear en mi programa curricular experiencias de éste tipo. ¿Las razones? Principalmente dos: una de ellas está centrada en lo motivacional, creo que para quien se mueve a diario en un ambiente escolar, no es un secreto la magia y encanto que produce en los estudiantes, el poder explorar y tener contacto con lo que se estudia, así como el ingresar al laboratorio y acceder a los instrumentos aunque pocos en la mayoría de los casos-. Precisamente Caamaño (2003, p. 96) resalta los trabajos prácticos como una de las actividades más importantes en la enseñanza de las ciencias enfatizando en ocho razones diferentes entre las cuales incluye "motivan al alumnado. Permiten un conocimiento vivencial de muchos fenómenos..."

A propósito de esto, en uno de mis relatos de clase, intento plasmar lo que alcanzo a percibir en los estudiantes al llevar a cabo una disección: "Todo transcurre en perfecta calma aunque, se respira un aire de ansiedad. Todos están inquietos como esperando el momento en que suene el pitazo inicial y puedan empezar (...) observo atenta lo que ocurre al interior de los grupos: se reparten labores, algunos se dedican a copiar, otros a observar sin tocar y los más intrépidos ejecutan la labor de cortar lentamente la esclerótica, de separar la córnea, de liberar el humor vítreo (...). Me sonrío al ver la cara de sorpresa de algunos (...) Transcurrido un rato, les pido que organicen los mesones algunos me preguntan que si me esperan en el salón para seguir trabajando yo les contesto que las dos horas de clase se terminaron y ellos se sorprenden... ¿ya profe?" Ruiz (2009)

La otra razón está centrada en mi como docente y en la imagen de ciencia que tengo, pienso la ciencia y especialmente la biología como el conjunto complejo de observaciones, registros rigurosos, sistematizaciones, discusiones conceptuales y construcciones colectivas surgidas de la confrontación de la propia experiencia, del planteamiento de suposiciones y los fundamentos teóricos. De allí, que promueva

${ }^{1}$ Profesora Departamento de Biología, Universidad Pedagógica Nacional. doruva15@hotmail.com 
en mis estudiantes el ejercicio de estos trabajos prácticos, que junto a otras actividades como discusiones, producciones escritas, sustentaciones, mesas redondas, etc. busquen alcanzar, en los estudiantes, los fines de la enseñanza de la biología que plantea Banet (2000): "reconocer la unidad y diversidad de los seres vivos, conocer los aspectos básicos de su estructura y funcionamiento...identificar las relaciones que los seres vivos establecen con el medio en el que viven...evaluar los beneficios personales y/o sociales que se deriven de determinados comportamientos e interpretar un buen número de acontecimientos que suceden fuera de las aulas"

En el párrafo anterior hablo de mi concepción sobre la naturaleza de las ciencias porque las ideas, representaciones o imaginarios que tengo como docente acerca de ello, direccionan mi didáctica, es decir que, éstas tienen implicaciones en la enseñanza, entendiendo la naturaleza de la ciencia como aquello que da respuesta a qué es la ciencia, cómo funciona internamente, cómo se desarrolla, cómo construye su conocimiento, cómo se relaciona con la sociedad, consensos a los que - vale la pena resaltar - ha sido difícil llegar aún entre los propios científicos. Vásquez et al. (2004)

Quizás una de las experiencias que mejor pueden ilustrar la concepción de ciencia que describí atrás y como ésta influye en mis modos y maneras de enseñar, fue una realizada con niños de grado sexto: "Se hicieron varios ejercicios que contemplaban mediciones, observaciones, descripciones, formulación de hipótesis, tabulación y graficación (...) se procedió a organizar grupos de máximo 5 estudiantes (...) Cada grupo debía llegar a un acuerdo, en cuanto al organismo con el que querían realizar su experiencia. (...) así que debían formular una pregunta, hacer una revisión bibliográfica, proponer una experiencia y diseñar una tabla en la cual registrarían datos. (...).Cuando se reunieron en grupo, sabía que iban a surgir muchos inconvenientes, pero mi intención era que ellos aprendieran a resolverlos y a trabajar cooperativamente. Se disgustaron, enfadaron, discutieron, se reconciliaron y aunque con dificultades los grupos trataron de mantenerse. Cuando expusieron lo que querían hacer, sobresalían algunos estudiantes por sus habilidades comunicativas y su buen nivel de comprensión del trabajo a desarrollar. Algunos grupos diseñaron unas tablas no muy convenientes así que los demás compañeros pasaban y les proponían alternativas. Creo que se lograron buenos niveles de análisis" Ruiz (2009)

En éste punto se hace necesario aclarar que la Biología a diferencia de la Física y la Química posee otras maneras en la producción de conocimiento como la narrativa histórica y ya que su objeto de estudio es lo vivo existen múltiples limitaciones en la experimentación y, mejor aún, la biología evolutiva en su mayor parte no es una ciencia de laboratorio, ésta sólo puede recurrir a procedimientos experimentales restringidos. Caponi (2003).

Mayr (2006) habló de la biología como una ciencia única y siendo consecuentes con ello, ésta requiere de una didáctica única que aproxime a los estudiantes a los fundamentos históricos y epistemológicos de la misma.

Caponi (2003, p.77) hace una clara diferencia entre la observación y el experimento en biología, para él "la jaula, el acuario, el invernadero, el cultivo experimental, el tubo de ensayo o cualquier otro artificio con el que se puedan aislar los procesos biológicos, le servirán como simples recursos para tornar 
visible aquello que ocurre en la naturaleza pero que, por alguna razón, ella no nos permite ver con claridad: el laboratorio se transforma en una ventana a la naturaleza. El experimento en cambio, es otra cosa, es producir y variar condiciones para determinar el efecto que ese cambio produce sobre ciertos fenómenos". Ahora bien, si la biología es una ciencia observacional, los docentes al implementar trabajos prácticos, debemos tener claro lo que menciona Caponi (2003) con respecto a la observación, aludiendo que ésta es una realización práctica y la clave no esta en lo puramente receptivo y ocasional de la misma, no se puede homologar observación a una simple contemplación ya que la observación científica es metódica, ordenada y exige una activa búsqueda de lo que debemos y queremos observar.

Es así como en mi práctica docente, procuro movilizar el pensamiento de los estudiantes, promoviendo experiencias que permitan hacer observaciones diarias, registro y narraciones de las mismas para después ser contrastadas con la teoría y confrontadas con sus propias ideas. Procuro entrar en un diálogo con ellos, que busca cuestionarlos constantemente:

"Primero cuéntenme cómo era la uva pasa antes de colocarla en el agua"

Varios niños a la vez: jarrugadita!, jchiquita!

Bien, ¿De qué esta hecha esa uva pasa?

Un silencio total... así que les ayudo: ¿De dónde se sacan las uvas?

Veo caritas con deseos de responder pero no se animan y al fin una tímida voz pregunta: ¿de una mata?

Eso muy bien, ¡de una planta! ¿Han visto los racimos de uvas?

Todos: jsi!

Entonces si las uvas son tomadas de una planta y las plantas son seres vivos ¿De qué esta hecha esa uva pasa?

Algunas manos levantadas, le doy la palabra a uno de ellos y me contesta que de células.

Yo lo felicito y digo: ¡Exacto!, muy bien.(...)

Bien entonces volvamos a nuestra experiencia. Si sabe a dulce, el azúcar será el soluto. ¿Cuál medio está más concentrado? ¿El interior de las células o el agua?

El interior (...)

Bien, ¿Quién me cuenta que ocurrió entonces con la uva en esos cinco días? Yo lo voy dibujando.

Hago cinco vasos y mientras el estudiante relata lo que observó yo lo ilustro en el tablero.

Me dijo: "Cada día que iba y la miraba estaba más y más grande, se iba hinchando y parecía una uva de verdad, el agua se puso blanca y soltaba burbujas y al final la uva se rompió" Ruiz (2009)

En mi consideración, al llevar a cabo trabajos prácticos en la clase de biología, se observan resultados en el aprendizaje de los estudiantes, algo fundamental se logra: captar la atención de ellos; una vez logrado esto, la pedagogía del maestro cobra vigencia en todo su esplendor, ya que en ese momento debe hacer gala de su didáctica, de tal suerte que favorezca en los estudiantes habilidades de orden superior. Pero también creo, que hasta ahí puede el docente hacer, la otra parte corresponde al estudiante. Probablemente por ello, Jiménez (2003) reporte múltiples investigaciones en las que los resultados de los trabajos prácticos no siempre son efectivos. 
En todo proceso de enseñanza - aprendizaje, el docente es responsable cien por ciento de lo primero (es decir de la enseñanza entendida no como la transmisión de información, sino como el acompañamiento, orientación y procura de ambientes de aprendizaje) y en parte, de lo segundo, ya que al estudiante no se le puede eximir de su responsabilidad en la consecución de logros en su propio proceso de aprendizaje.

Siempre he pensado que la última razón por la cual un estudiante va a la escuela es para aprender, Savater (1991) lo menciona claramente. Somos los adultos quienes tenemos consciencia de la importancia de la escuela, de su papel socializador y de su influencia en el desarrollo humano. Por ello, en una práctica los estudiantes deben ser estimulados constantemente; de manera muy sucinta puedo describir mi rol en el desarrollo de dichas actividades: "Paso por todos y cada uno de los grupos, los oriento, les indico como deben hacer la manipulación correcta del material trabajado, los interrogo sobre el funcionamiento de cada parte, los insto a describir cada estructura que encuentran, los induzco a hacer relaciones con otros temas vistos y los animo a comparar constantemente con la teoría". Ruiz (2009)

Una experiencia práctica debe estar pensada desde los contenidos a enseñar: conceptuales, actitudinales y procedimentales, ya que entre otras cosas, como lo menciona Coll et al (1992, p. 27) "supone un intento de romper con la práctica habitual... de una enseñanza centrada en exceso en la memorización más o menos repetitiva de hechos y en la asimilación más o menos comprensiva de conceptos...excluyendo otros...como si se creyera que... los alumnos pueden aprender los procedimientos y los valores por si solos sin necesidad de una ayuda pedagógica sistémica y planeada"

No son meros datos lo que se debe buscar en la enseñanza, se hace imperante una práctica que estimule la comprensión y los aprendizajes de la biología de una manera sistémica, holística relacional, donde los conceptos estructurantes y sus múltiples interrelaciones se puedan suscitar.

De igual manera, los trabajos prácticos deben promover las destrezas y habilidades propias de las ciencias, no solo lo relacionado con la manipulación de instrumental sino el registro ordenado, la observación juiciosa, la construcción de gráficos y los complejos cambios a nivel de la estructura mental que se logran al tratar de resolver situaciones problémicas y de versen obligados - los estudiantes - a plantear hipótesis, planear diseños experimentales, consultar fuentes o elaborar informes. A este respecto Banet (2000) explica que el estudio de los fenómenos biológicos en las aulas de la secundaria, permite aprender estrategias que les aproxime a los métodos de trabajo que caracterizan la investigación científica, lo cual en consecuencia hace que el estudiante se aproxime a la naturaleza de la ciencia, como por ejemplo su carácter provisional.

En cuanto a lo actitudinal, yo planteo dos maneras de promover esto, una está relacionada con el trabajo propio durante la experiencia práctica que favorece el trabajo colaborativo lo cual conlleva diálogo, tolerancia, respeto a los diferentes puntos de vista y aprecio por la diversidad de argumentos; la otra está relacionada con las actitudes que se pueden enseñar desde la biología, como son el valor por la diversidad, aprecio de su propio ser, el respeto por lo vivo, 
su cuidado y responsabilidad. A éste respecto es bueno recordar que tal como lo plantea Jiménez (2003) para hacer que los valores ambientales pasen de lo declarativo a la acción, o en sus propias palabras "se traduzca en tomas de decisiones y comportamientos coherentes", deben tener una base o fundamentación teórica, de lo contrario serán tan sólo apreciaciones.

La evaluación de los trabajos prácticos, está por lo tanto, pensada en la misma dirección, las preguntas típicas de la educación bancaria en la que se le pide al niño que repita sin ninguna lógica una serie de información se torna obsoleta. Es importante pensar que a través de los trabajos prácticos se busca una formación integral del estudiante, una formación que cobije el ser, saber y quehacer.

En conclusión, los trabajos prácticos, en mi consideración, son ineludibles en las clases de biología, no se pueden dejar de lado, a pesar de las dificultades y tropiezos que esto conlleve en la institución, incluso con poco material se pueden llevar a cabo y las ganancias son grandes. Las clases se tornan mas interesantes para los estudiantes, se abren espacios que ofrecen un acercamiento y otra mirada al trabajo en ciencias, se promueve un desarrollo integral logrando aprendizajes de tipo actitudinal, procedimental y cognitivo y se incita al estudiante a argumentar, defender y contrastar sus propias ideas.

Por lo tanto, la manera de orientar los trabajos prácticos debe inducir a los estudiantes a hacer uso de heurísticos más que de algoritmos y hacer relevante en ellos, el qué, el cómo y el para qué de la biología.

Lo que está en juego es el desarrollo de nuestros estudiantes y por ello, bien vale la pena el esfuerzo.

Por otra parte, considero que los trabajos prácticos además de incrementarse en las aulas de biología, deben mantener un carácter reflexivo desde la práctica del docente, ya que solo de ésta manera el saber que circula en las aulas cobra valor y se convierte en un saber dinámico y susceptible de mejoramiento.

\section{Bibliografía}

- BANET HERNANDEZ, E. 2000. La enseñanza y el aprendizaje del conocimiento Biológico. Didáctica de las Ciencias Experimentales. Capítulo 19, p. 449--478.

- CAPONI, G. 2003. Experimentos en Biología Evolutiva. ¿Qué tienen ellos que los otros no tengan? Espíteme, Porto Alegre, 16, p. 61 - 97

- COLL, C.; POZO, J.I. y SARABIA, B 1992 Los contenidos en la Reforma. Enseñanza y aprendizaje de conceptos, procedimientos y actitudes. Madrid: Santillana.

- JIMENEZ ALEIXANDRE, M.P. 2003 La enseñanza y el aprendizaje de la Biología. Enseñar Ciencias. Serie didáctica de las ciencias experimentales. Capitulo 6. Jiménez Aleixandre M.P. (coord). Barcelona Grao editorial. 
- CAAMAÑO, A. 2003 Los trabajos prácticos en Ciencias. Enseñar Ciencias. Serie didáctica de las ciencias experimentales Capítulo 5, p. 95 -118. Jiménez Aleixandre M.P. (coord). Barcelona Grao editorial.

- MAYR, E. 2006 Por qué es única la Biología. Consideraciones sobre la autonomía de una disciplina científica. Katz editores. Buenos Aires. 280 p.

- RUIZ V, D. 2009 Relatos de Clase. Construcción realizada para el Seminario de Pedagogía y Didáctica de la Especialización en Enseñanza de las Ciencias. Universidad Pedagógica Nacional (Colombia). Sin publicar

- SAVATER, F. 1991. El valor de Educar. Editorial Ariel, S.A. Barcelona. 286 p.

- VASQUEZ, A.; ACEVEDO, J.A. y MANASSERO, M.A 2004 Consensos sobre la naturaleza de la Ciencia: Evidencias e Implicaciones para su enseñanza. Revista Iberoamericana de Educación (ISSN: 1681-5653), edición electrónica De los Lectores, sitio de internet: http://www.campus-oei.org/revista/deloslectores/702Vazquez.PDF. 